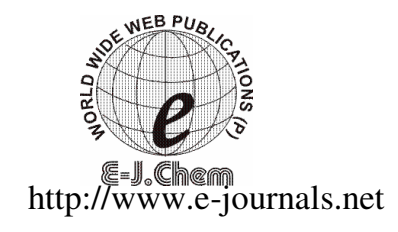

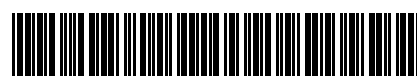

ISSN: 0973-4945; CODEN ECJHAO

E-Journal of Chemistry

2010, 7(S1), S67-S72

\title{
Polyethelene Glycol-Anthranilic Acid Composite as Corrosion Inhibitor for Mild Steel in Acid Medium
}

\author{
N.BANUMATHI", S. SUBHASHINI and R.RAJALAKSHMI \\ *Department of Chemistry \\ SriGuru Institute of Technology, Saravanampatti Coimbatore-641110, India \\ Department of Chemistry \\ Avinashilingam University for Women, Coimbatore-641043, India \\ banumathi.sh@sriguru.ac.in
}

Received 29 January 2010; Accepted 20 March 2010

\begin{abstract}
The polymer PGA composite was prepared by chemical oxidative method of polyethylene glycol, anthranilic acid with ammonium persulphate in oxalic acid medium. The resulted polymer was characterized by FTIR spectroscopy. The performance of the polymer polyglycol anthranilic acid composite (PGA) as corrosion inhibitor for mild steel in $1 \mathrm{M} \mathrm{HCl}$ has been studied by weight loss, potentiodynamic and impedance spectroscopy methods. The maximum IE was found to be $97 \%$. Experimental results were fitted to Langmuir adsorption isotherm. Electrochemical studies confirmed the inhibitive nature of the PGA composite and also the mixed nature of the inhibitor. The polymer is found to be highly efficient non-toxic and environmentally safe.
\end{abstract}

Keywords: PGA, $\mathrm{HCl}$, Mild steel, Corrosion.

\section{Introduction}

Corrosion of metals in different environment is one of the serious problems facing the industries and its prevention has been approached from various angles like surface coating, plating and alloying. Technological and financial considerations may sometimes favour the addition of inhibitors to reduce the corrosion rate. Inhibition of corrosion of mild steel is a matter of theoretical as well as practical importance ${ }^{1}$. Compounds containing nitrogen, sulphur and oxygen have been reported as inhibitors ${ }^{2-6}$. The most efficient organic inhibitors are organic compounds having unsaturated bonds in their structures ${ }^{7}$. Most of the conducting polymers have extensively delocalized $\pi$ electrons, in abundance, should enable them to be good corrosion inhibitors. The adsorption of these compounds is influenced by various factors viz. (i) electronic structure of inhibiting molecules, (ii) steric factor, (iii) aromaticity, (iv) electron density at donor site, (v) presence of functional group such as $-\mathrm{CHO},-\mathrm{N}=\mathrm{N}, \mathrm{R}-\mathrm{OH}$ in the inhibitor molecule, (vi) molecular area and (vii) molecular weight of the inhibitor molecule ${ }^{8-12}$. 
Conducting polymers are becoming the most promising new materials for next generation electrical and electronic devices ${ }^{13,14}$. These polymers have also been recognized as excellent corrosion inhibitors for metals in acid environment ${ }^{15-20}$. Recently polymer amines $^{21,22}$ were evaluated due to their higher inhibition efficiency on the corrosion of mild steel in acid solutions. Owing to the multiple adsorption sites, polymeric compounds adsorb more strongly on the metal surface compared with their monomer analogues ${ }^{23}$. Polyaniline and its derivatives have versatile applications in plastic batteries, harmonic generators, display devices, solid state sensors and corrosion inhibitors ${ }^{24-26}$. Polyaniline and its derivatives are key effective corrosion inhibitors in acid chloride solution due to the presence of $\pi$ electrons, quaternary nitrogen atom and large molecular size, which ensures greater coverage of the metallic surface, which leads to higher inhibition efficiency.

A study was undertaken with polyethelene glycol-anthranilic acid composite as an inhibitor for mild steel in acidic aqueous solution. The inhibition efficiency was estimated by Tafel extrapolation method, linear polarization resistance method, impedance spectroscopy and direct weight loss method. Before use, the characterization of polymer composite was carried out by recording FTIR spectrum.

\section{Experimental}

The polymer PGA composite was synthesized as described by Rupali Gangopadhayan et.al ${ }^{27}$. The infrared spectra of the polymer was recorded on a Perkin Elmer FTIR. The evaluation of this polymer as corrosion inhibitor was carried by electrochemical techniques and direct weight loss method. Weight loss experiments were carried out in triplicate by using $1 \times 5 \mathrm{~cm}^{2}$ mild steel strips for duration of $1 / 2 \mathrm{~h}, 3 \mathrm{~h}, 6 \mathrm{~h}, 12 \mathrm{~h}$ and $24 \mathrm{~h}$ at $303 \mathrm{~K}, 313 \mathrm{~K}, 323 \mathrm{~K}$ and $343 \mathrm{~K}$.

For electrochemical studies a three electrode cell with $1 \mathrm{~cm}^{2}$ mild steel as working electrode, a saturated calomel electrode (SCE) as the reference electrode and platinum foil as the counter electrode was used. The working electrode was polished before use. Before starting the electrochemical experiments the test sample was allowed to reach steady state after immersion in the solution.

Impedance studies were performed for the mild steel in $1 \mathrm{M} \mathrm{HCl}$ at $26+2{ }^{\circ} \mathrm{C}$ in the absence and presence of polymer composite PGA at $\mathrm{E}_{\text {corr }}$ with the a.c.voltage amplitude $10 \mathrm{mV}$ in the frequency range $10 \mathrm{KHz}$ to $10 \mathrm{MHz}$. A time interval of a few minutes was given for the o.c.p to read a steady value.

\section{Results and Discussion}

\section{Effect of concentration and immersion time}

Weight loss experiments showed the effective action of the polymer composite as corrosion inhibitor of MS in $\mathrm{HCl}$ solution. Values of IE of different concentration of the polymer for all test durations are given in Table 1. IE increased with increase in concentration of the polymer and maximum IE was noticed with $1.7 \%$ concentration. The IE increased with increase in immersion time up to $12 \mathrm{~h}$, showing decrease at $24 \mathrm{~h}$.

The inhibition of corrosion by the polymer in $1 \mathrm{M} \mathrm{HCl}$ may be due to the adsorption of polymer molecules on the metal surface thus preventing the dissolution of iron. An increase in number of additive molecules the blockage of active sites on the metal surface increases. Consequently the inhibition increased. It may be assumed that due to greater rate of adsorption during the first few hours of immersion the IE enhanced with time. 
Table 1. Inhibition efficiency as a function of immersion time and concentration

\begin{tabular}{ccccccc}
\hline Conc, \% & \multicolumn{7}{c}{ IE, \% } & & \\
\hline & $0.5 \mathrm{~h}$ & $1 \mathrm{~h}$ & $3 \mathrm{~h}$ & $6 \mathrm{~h}$ & $12 \mathrm{~h}$ & $24 \mathrm{~h}$ \\
0.1 & 32.1 & 39.5 & 25.8 & 21.6 & 40.4 & 15.1 \\
0.3 & 32.7 & 48.9 & 41.2 & 43.1 & 56.1 & 43.5 \\
0.5 & 50.3 & 53.7 & 51.8 & 55.9 & 69.7 & 68.2 \\
0.7 & 57.3 & 69.2 & 56.1 & 59.3 & 74.1 & 85.9 \\
0.9 & 61.7 & 72.1 & 65.8 & 61.3 & 76.5 & 92.1 \\
1.3 & 65.7 & 80.2 & 68.1 & 67.1 & 79.5 & 96.1 \\
1.7 & 67.3 & 81.4 & 97.1 & 86.7 & 86.4 & 96.8 \\
1.9 & 68.1 & 82.5 & 96.1 & 86.6 & 78.1 & 92.8 \\
\hline
\end{tabular}

\section{Influence of temperature}

The loss in the weight of steel samples in $1 \mathrm{M} \mathrm{HCl}$ in the absence and presence of various concentrations of PGA composite at different temperatures were determined. The effect of temperature on the inhibition efficiency of the polymer is shown in Table 2. In all cases, increase in PGA composite concentration leads to a decrease in the corrosion rate of samples indicating that the presence of polymer composite retards the general corrosion of samples in $1 \mathrm{M} \mathrm{HCl}$.

On the other hand, an increase in temperature from 333-343 K resulted in an increase in the corrosion rate for all polymer composite solution, probably as a result of desorption of inhibitor molecules from the metal surface.

Table 2. Variation of PGA at different temperature

\begin{tabular}{|c|c|c|c|c|c|c|c|c|c|c|c|}
\hline \multicolumn{12}{|c|}{ Temperature, $\mathrm{K}$} \\
\hline \multirow[b]{2}{*}{ S.No } & \multirow{2}{*}{$\begin{array}{c}\text { Conc, } \\
\%\end{array}$} & \multicolumn{2}{|c|}{303} & \multicolumn{2}{|c|}{313} & \multicolumn{2}{|c|}{323} & \multicolumn{2}{|c|}{333} & \multicolumn{2}{|c|}{343} \\
\hline & & $\mathrm{CR}$ & $\begin{array}{c}\text { IE, } \\
\% \\
\end{array}$ & CR & $\begin{array}{c}\mathrm{IE}, \\
\%\end{array}$ & $\mathrm{CR}$ & $\begin{array}{c}\text { IE, } \\
\%\end{array}$ & $\mathrm{CR}$ & $\begin{array}{c}\mathrm{IE}, \\
\%\end{array}$ & $\mathrm{CR}$ & $\begin{array}{l}\text { IE, } \\
\%\end{array}$ \\
\hline 1 & 0.1 & 1115.53 & 32.1 & 929.8 & 41.6 & 3518 & 21.6 & 5816.8 & 13.3 & 9119.6 & 11.9 \\
\hline 2 & 0.3 & 1104.19 & 32.7 & 853.9 & 46.3 & 2398 & 46.5 & 4826.7 & 28.1 & 7905.5 & 23.5 \\
\hline 3 & 0.5 & 816.37 & 50.3 & 770.1 & 51.6 & :136 & 52.4 & 4232.7 & 36.9 & 8285.8 & 23.6 \\
\hline 4 & 0.7 & 701.24 & 57.3 & 705.6 & 55.7 & 963 & 56.2 & 3584.7 & 46.6 & 7782.6 & 24.8 \\
\hline 5 & 0.9 & 627.1 & 61.7 & 630.6 & 57.6 & 1849 & 58.8 & 3530.6 & 47.3 & 66503.9 & 37.1 \\
\hline 6 & 1.3 & 563.43 & 65.7 & 613.2 & 61.5 & 1580 & 64.8 & 2665.4 & 60.3 & 6294.6 & 39.1 \\
\hline 7 & 1.7 & 536.39 & 67.3 & 553.8 & 65.2 & 1356 & 69.8 & 2599 & 61.2 & 6269.3 & 39.4 \\
\hline 8 & 1.9 & 525.93 & 68.1 & 498.9 & 68.6 & :18.1 & 81.8 & 1721.7 & 74.3 & 4456 & 57.9 \\
\hline
\end{tabular}

\section{Adsorption isotherm}

The phenomenon of interaction between the metal surface and inhibitor can be better understood in terms of adsorption isotherm. A plot of $\log \Theta / 1-\Theta V s . \log \mathrm{C}$ Figure 1 gave a straight line with approximately unit slope indicating that the inhibitor under study obeys Langmuir adsorption isotherm. The deviation from unity may be explained on the basis of the interaction between the adsorbed spieces on the metal surface. It has been postulated in the derivation of Langmuir isotherm equation that the adsorption molecules do not interact with each other. This is not true in case of organic or polymer molecules having polar atoms or groups which are adsorbed on the anodic and cathodic sites of the metal surface .Such adsorbed species may interact by mutual repulsion or attraction ${ }^{28}$. 


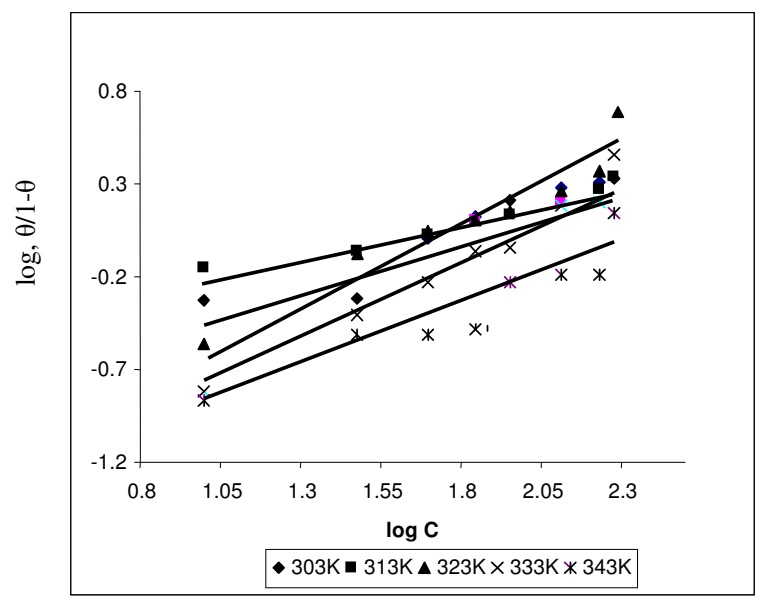

Figure 1. Langmuir adsorption Isotherm

The regression co-efficients were calculated for Langmuir adsorption isotherm. The values of $\mathrm{R}^{2}$ generally lie between 0 and 1 .The closer the value of $\mathrm{R}^{2}$ lies to 1 , the better the regression line to data. The $\mathrm{R}^{2}$ values were significant at one percent level.

\section{Activation energy ( $E a)$}

Corrosion rate of mild steel in presence of PGA composite by weight loss method are plotted against temp $(\log \mathrm{CR} v s .1 / \mathrm{T})$. Activation energies are calculated from the slope. It was observed for $\mathrm{HCl}$ solution the $\mathrm{Ea}$ as $44.128 \mathrm{~kJ} / \mathrm{mole}$. In the presence of the inhibitor the activation energies are increased compared to the acid solution revealing the retardation of the corrosion reaction. The marked changes in Ea suggest that the inhibitor may either participate in the electrode or may change the potential difference of the metal solution interface by adsorption.

\section{Thermodynamic parameters}

\section{Free energy change}

The values of free energy of adsorption $(\Delta \mathrm{G})$ were calculated using the standard equation

$$
\begin{aligned}
& \log C=\log \Theta /(1-\Theta)-\log B \\
& \text { where, } \log B=-1.74-(-\Delta G / 2.303 R T) \\
& \Theta=\text { Surface coverage } \\
& C=\text { Concentration } \\
& R=\text { Gas Constant } \\
& T=\text { Temperature }
\end{aligned}
$$

The calculated free energy of adsorption (Table 3 ) ranged between $-27.5 \mathrm{~kJ}$ to $-21.8 \mathrm{~kJ}$. The negative free energy values indicate the spontaneous adsorption of inhibitor and the strong interaction between the metal surface and the inhibitor molecule. The increase in $-\Delta \mathrm{G}$ with increasing concentration is an evidence for repulsive forces in the adsorption layer. Similar observations have been reported by Lillard R.S. et $a l^{29}$.

The values of $-\Delta \mathrm{G}_{\mathrm{ads}} \leq 20 \mathrm{~kJ} \mathrm{~mol}^{-1}$ are consistent with electrostatic interaction between the charged molecules and the charged metal surface. This is substantiated by the observation reported by Khamis et.al $(1991)^{30}$. 
Table 3. Thermodynamic and kinetic parameters for adsorption of PGA on MS surface

\begin{tabular}{|c|c|c|c|c|c|c|c|}
\hline \multirow{2}{*}{ Conc, $\%$} & \multirow{2}{*}{$\begin{array}{c}\mathrm{Ea}, \\
\mathrm{kJ} / \mathrm{mol}\end{array}$} & \multicolumn{4}{|c|}{$-\Delta \mathrm{G}, \mathrm{k} \mathrm{J} / \mathrm{mol}$} & \multirow{2}{*}{$\begin{array}{c}\Delta \mathrm{H}, \\
\mathrm{kJ} / \mathrm{mol}\end{array}$} & \multirow{2}{*}{$\begin{array}{c}\Delta \mathrm{S}, \\
\mathrm{kJ} / \mathrm{mol}\end{array}$} \\
\hline & & $313 \mathrm{~K}$ & $323 \mathrm{~K}$ & $333 \mathrm{~K}$ & $343 \mathrm{~K}$ & & \\
\hline & 51.990 & 27.5499 & 25.8787 & 25.0585 & 25.4481 & -49.3566 & 0.071258 \\
\hline 0.3 & 48.6277 & 25.1875 & 26.0138 & 24.6059 & 24.6581 & -34.9435 & 0.029961 \\
\hline & 54.4282 & 24.4105 & 25.2765 & 24.3073 & 23.2169 & -39.2259 & 0.045497 \\
\hline 0.7 & 55.2966 & 23.9641 & 24.7842 & 24.4841 & 22.4439 & -39.8628 & 0.048609 \\
\hline 0.9 & 55.0532 & 23.5114 & 24.3951 & 23.866 & 23.3853 & -26.7658 & 0.009074 \\
\hline 1.3 & 54.0653 & 22.976 & 24.0911 & 24.3045 & 22.5784 & -26.6998 & 0.009794 \\
\hline 1.7 & 55.4177 & 22.6928 & 23.9817 & 23.6662 & 21.8491 & -32.384 & 0.009794 \\
\hline 1.9 & 46.995 & 22.8032 & 25.4693 & 25.036 & 23.6687 & -17.1484 & -0.02163 \\
\hline
\end{tabular}

\section{Heat of adsorption}

The change in heat of adsorption $\Delta \mathrm{H}$ and change in Entropy $\Delta \mathrm{S}$ can be calculated using Gibbs Helmholtz equation

$$
\Delta \mathrm{G}=\Delta \mathrm{H}-\mathrm{T} \Delta \mathrm{S}
$$

A plot of $\Delta \mathrm{G}$ versus $\mathrm{T}$ will be a straight line with intercept $\Delta \mathrm{H}$ and slope $\Delta \mathrm{S}$. All the obtained values of $\Delta \mathrm{H}$ and $\Delta \mathrm{S}$ for the inhibitor adsorption on the mild steel surface were listed in Table 3.

The negative values indicated the exothermic adsorption behavior of the inhibitor at the experimental temperatures studied. The average value of $\Delta \mathrm{H}$ is about $33.29 \mathrm{~kJ} / \mathrm{mol}$ which is larger than common physical adsorption heat but smaller than the common chemical adsorption heat ${ }^{31}$ probably meaning comprehensive adsorption (physical and chemical). That is to say, since the adsorption heat approached the general chemical reaction heat, the chemical adsorption might occur accompanied by physical adsorption (electrostatic interaction) $)^{32}$.

\section{Entropy change}

When adsorption increases the entropy will decrease. For an exothermic adsorption process also the entropy will decrease. The decrease in positive value of $\Delta \mathrm{S}$ with increase in concentration of the inhibitor (Table 3) proved the exothermic adsorption of the inhibitor on the metal surface.

\section{Electrochemical measurements}

\section{Polarization studies}

Typical potentiodynamic polarizing curve showing the inhibitive action of PGA is given in Figure 2. The corrosion parameters calculated from the polarization curves are tabulated in Table 4. $\mathrm{I}_{\text {corr }}$ was found to decrease as the inhibitive action of PGA composite on metal surface. The $\mathrm{E}_{\text {corr }}$ values and observation of curve infers that there is change in both anodic and cathodic polarization with the addition of inhibitor. This indicates that the inhibitor acts through mixed mode of inhibition. The decrease in both Tafel constants ba and bc value of concentration with increase in concentration of the inhibitor up to $0.5 \%$, suggest that both anodic dissolution and cathodic hydrogen evolution mechanism are affected in presence of the inhibitor. It can be concluded from the results obtained that PGA act as a mixed inhibitor. In addition, no significant change in $\mathrm{E}_{\text {corr }}$ value was observed, which suggests a mixed type of inhibition effect of polymer ${ }^{33}$. 


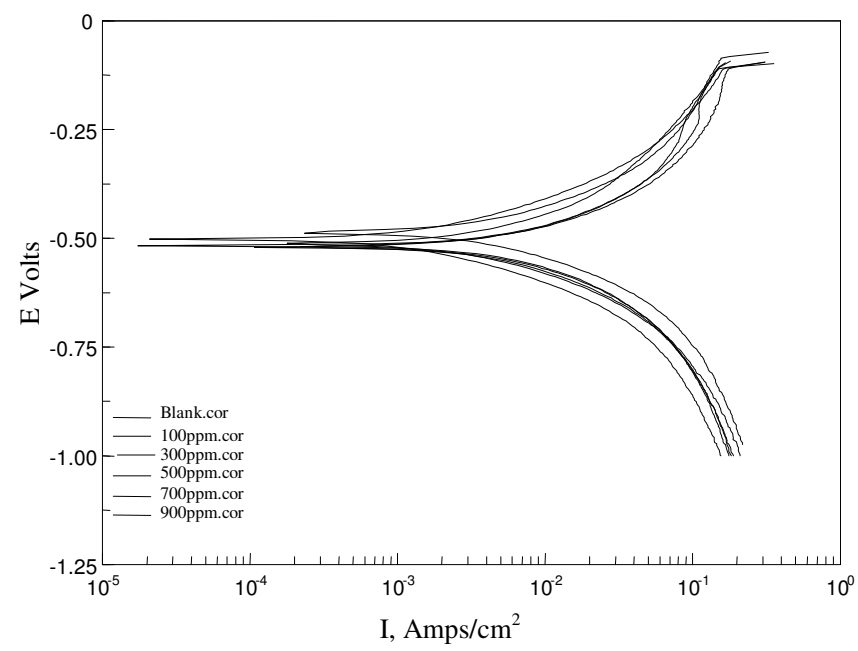

Figure 2. Polarization curve of $\mathrm{MS}$ in presence of PGA in $0.1 \mathrm{M} \mathrm{HCl}$

Table 4. Electrochemical and corrosion parameters for MS in the presence of PGA in $1 \mathrm{M} \mathrm{HCl}$

\begin{tabular}{cccccccc}
\hline Conc, \% & $\begin{array}{c}\mathrm{E}_{\text {corr }} \\
\text { Amp/cm) }\end{array}$ & $\begin{array}{c}\mathrm{I}_{\text {corr }}{ }^{*} \\
10^{-4}\end{array}$ & Ba, mV & Ba(mV) & IE\% & $\begin{array}{c}\text { Rp } \\
\text { (ohm/cm) }\end{array}$ & IE\% \\
\hline Blank & 522 & 54.7 & 265 & 190 & - & 4.77 & - \\
0.1 & 517 & 48.9 & 202 & 183 & 10.6 & 5.33 & 10.5 \\
0.3 & 519 & 47.9 & 192 & 180 & 12.4 & 5.43 & 12.2 \\
0.5 & 512 & 34.6 & 151 & 156 & 36.7 & 7.53 & 36.7 \\
0.7 & 513 & 30.3 & 154 & 162 & 44.6 & 8.60 & 44.5 \\
0.9 & 501 & 14.7 & 126 & 117 & 73.1 & 17.6 & 72.9 \\
\hline
\end{tabular}

\section{Impedance studies}

The inhibitive action is enhanced by the protective barrier on the metal surface which is indicated from the increase of Rct values with increase in inhibitor concentration. The existence of single semi circle showed the single charge transfer process during dissolution which is unaffected by the presence of inhibitor molecules. The decrease in Cdl values for higher concentrations is attributed to increase in thickness of electronic double layer ${ }^{34}$. The increase in Rct value is attributed to the formation of protective film on the metal/solution interface ${ }^{35,36}$. The charge transfer resistance (Rct) and the interfacial double layer capacitance $(\mathrm{Cdl})$ derived from these curves are given in Table 5.

Table 5. Electrochemical and Impedance parameters of MS in the presence of PGA

\begin{tabular}{cccc}
\hline Conc, ppm & Rct, ohm cm & IE, \% & $\mathrm{Cdl} \times 10^{-4,} \mu \mathrm{Fcm}$ \\
\hline Blank & 14.79 & - & 3.43 \\
0.1 & 17.43 & 15.2 & 4.10 \\
0.3 & 22.04 & 32.9 & 4.32 \\
0.5 & 40.46 & 63.5 & 2.33 \\
0.7 & 43.74 & 66.1 & 2.99 \\
0.9 & 72.32 & 78.5 & 1.18 \\
\hline
\end{tabular}


The probable mechanism is adsorption of the active species on the metal surface is revealed from the $\mathrm{Cdl}$ values which were found to decrease with increase in concentration of PGA. The depressed semicircle in Nyquist plot Figure 3 indicates that adsorption of the inhibitor molecule is charge transfer controlled. Maximum IE using Rct values was found to be $78.5 \%$ with $1.9 \%$ of concentration.

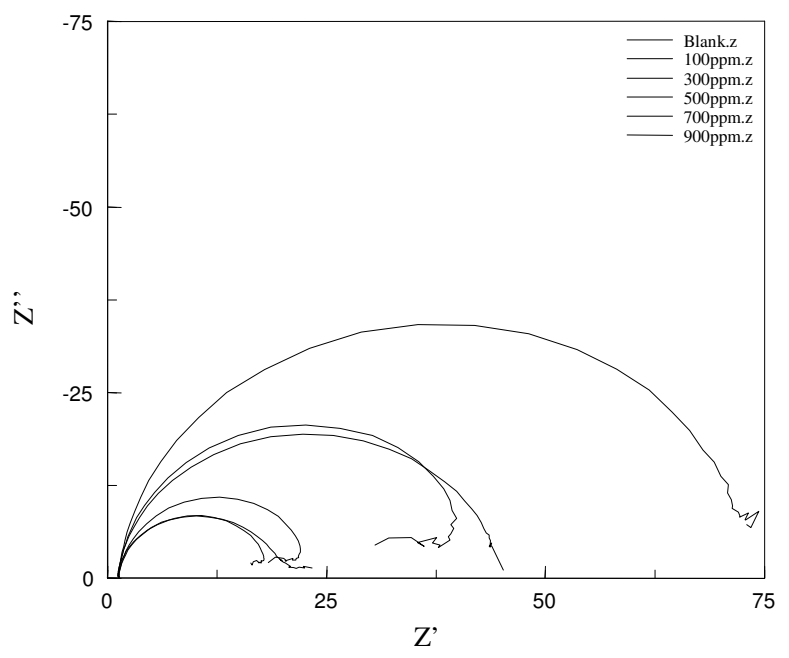

Figure 3. Nyquist Plot of MS in presence of PGA

\section{Mechanism of Inhibition process}

The mechanism of corrosion inhibition may be explained on the basis of adsorption behaviour $^{37}$. The inhibitive behaviour of self doped polyethelene glycol anthranilic acid (ortho carboxylated polyethelene glycol aniline) is reported for the first time.

Corrosion inhibition of mild steel in hydrochloric acid solution by polyanthranilic acid had been explained on the basis of molecular adsorption. The compound inhibits corrosion by controlling both the anodic and cathodic reactions. In acidic solution the polyglycol anthranilic acid exists as protonated species. These protonated species adsorb on the cathodic sites of the mild steel and decrease the evolution of hydrogen. The adsorption on anodic sites occurs through long $\pi$ electrons of aromatic rings (benzenoid and quinoid) and lone pair of electrons of nitrogen atoms, which decreases anodic dissolution of mild steel ${ }^{38}$. The high performance of the polymer is attributed to the presence of long $\pi$-electrons conjugation, quaternary nitrogen atom and the larger molecular size.

\section{Conclusion}

The PGA was proved to be a good inhibitor for MS in $1 \mathrm{M} \mathrm{HCl}$. The IE increase with inhibitor concentration, time and temperature. It obeys Langmuir adsorption isotherm. Kinetic and thermodynamic parameters infer the strong adsorption of inhibitor molecule on MS surface also the inhibition is by spontaneous physical adsorption of inhibitor on MS surface. Electrochemical measurements indicate the mixed mode of inhibition. Thus the polymer PGA inhibitor was proved to be an effective eco friendly inhibitor. 


\section{References}

1. Ali S A, Saeed M T and Rahman S V, Corros Sci., 2003, 45, 253-266.

2. Lagrenee M, Mernari B, Bouanis M, Traisnel M and Bentiss F, Corros Sci., 2002, 44, 573-588.

3. Quraishi M A and Sardar R, Corrosion, 2002, 58, 747-756.

4. Quraishi M A, Athar M and Ali H, Brit Corros J., 2002, 37, 155-158.

5. $\quad$ Quraishi M A and Ansari F A, J Appl Electrochem., 2003, 33(3-4), 233-238.

6. Quraishi M A and Khan S, J Appl Electrochem., 2006, 36, 539-544.

7. $\quad$ Schmitt G, Brit Corros J., 1984, 19, 165-176.

8. Bentiss F, Lagrenee M, Traisnel M and Hornez J C, Corros Sci., 1999, 41, 789-803.

9. McCaerty E, Pravdic V and Zettlemoyer A C, Trans Faraday Soc., 1999, 66, 237.

10. Growcok F B, Frenier W W and Andrezzi P A, Corrosion, 1989, 45, 1007.

11. Lukovits L, Kalman E and Palinkas G, Corrosion, 1995, 51, 201.

12. Ayers Jr R C and Hackerman N, J Electrochem Soc., 1963, 110(6), 507-513.

13. Skotheim T A, Elsenbaumer R L and Reynolds J R, Handbook of Conducting Polymer, Second Ed., Marcel Dekker Inc., New York, 1998.

14. Wang H L, MacDiarmid A G, Wang Y Z, D D Gebier and Epstein A J, Synth Met., 1996, 78, 33.

15. Rohwerder M and Michalik A, Electrochim Acta, 2007, 53, 1300-1313.

16. Riaz U, Ashraf S M and Ahmad S, Prog Org Coat., 2007, 59(2), 138-145.

17. Jeyaprabha C, Sathiyanarayanan S and Venkatachari G, Appl Surf Sci., 2006, 253, 432-438.

18. De Souza S, Surf Coat Technol., 2007, 201, 7574-7581.

19. Armelin E, Oliver R, Liesa F, Iribarren J I, Estrany F and Alemán C, Prog Org Coat., 2007, 59, 46-52.

20. da Silva J E P, de Torresi S I C and Torresi R M, Prog Org Coat., 2007, 58, 33-39.

21. Kusch P, Knupp G, Hergarten M, Kozupa M and Majchrzak M, Int J Mass Spectrom., 2007, 263(1), 45-53.

22. Alsabagh A M, Migahed M A and Awad H S, Corros Sci., 2006, 48, 813-828.

23. Ali S A and Saeed M T, Synthesis and corrosion inhibition study of some 1,6hexanediamine-based $N, N$-diallyl quaternary ammonium salts and theirpolymers, Polymer 2001, 42, 2785-2794.

24. Kitani A, Kaya M and Saski K, J Electrochem Soc., 1986, 133, 1069.

25. Huang J, Virji S, Weiller B H and Kaner R B, J Am Chem Soc., 2003, 125(2), 314.

26. Lu W K, Elsenbeumer R L and Wesiling B, Synth Met., 1995, 71, 2163.

27. Rupali Gangopadhayay, Amitabha De and Gowtram Ghosh, Synth Met., 2001, 123, 21-31

28. Fouda A S and El -Dafrawy H, Int J Electrochem Sci., 2007, 2, 721 - 733

29. Lillard R S and Butt D P, Corr Sci., 1997, 39(9), 1605-1624.

30. Khamis E, Bellucci F, Latanision R M and El-Ashry E S H, Corrosion, 1991, 47, 67.

31. Mu G, Li X and Liu G, Corros Sci., 2005, 47, 1932.

32. E A Noor, Int J Electrochem Sci., 2007, 2, 996-1017.

33. Jayaprabha C, Sathiyanarayan S, Phani K L N and Venkatachari G, J Electroanal Chem., 2005, 358, 250-255.

34. McCaffertyv E, Hackerman N and Tsai S, Corrosion, 1982, 38, 57-62.

35. Bentiss F, Traisnel M and Lagrenee M, Corros Sci., 2000, 42, 127-146.

36. Murlidharan S, Phani K L N, Pitchumani S, Ravichandran S and Iyer S V K, $J$ Electrochem Soc., 1995, 142, 1478-1483.

37. Hirozawa S T, in: Proceedings of the $8^{\text {th }}$ Eur Symp Corrosion Inhibition, Ann University, Ferrara, Italy, 1995, 1, 25.

38. Quraishi M A, Rawat J and Ajmal M , J Appl Electrochem., 2000, 30, 745-751. 


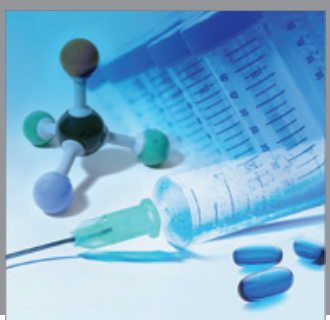

International Journal of

Medicinal Chemistry

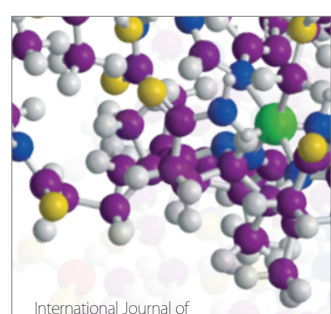

Carbohydrate Chemistry

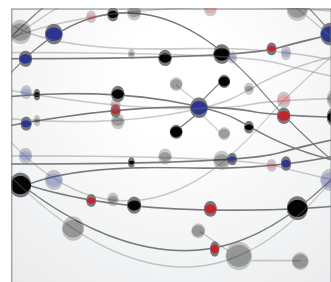

The Scientific World Journal
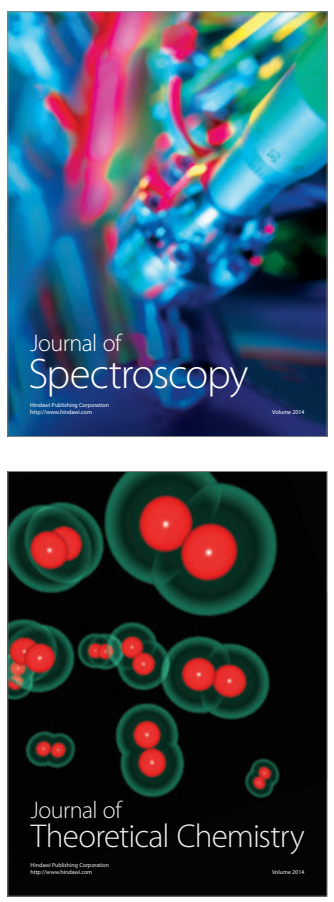
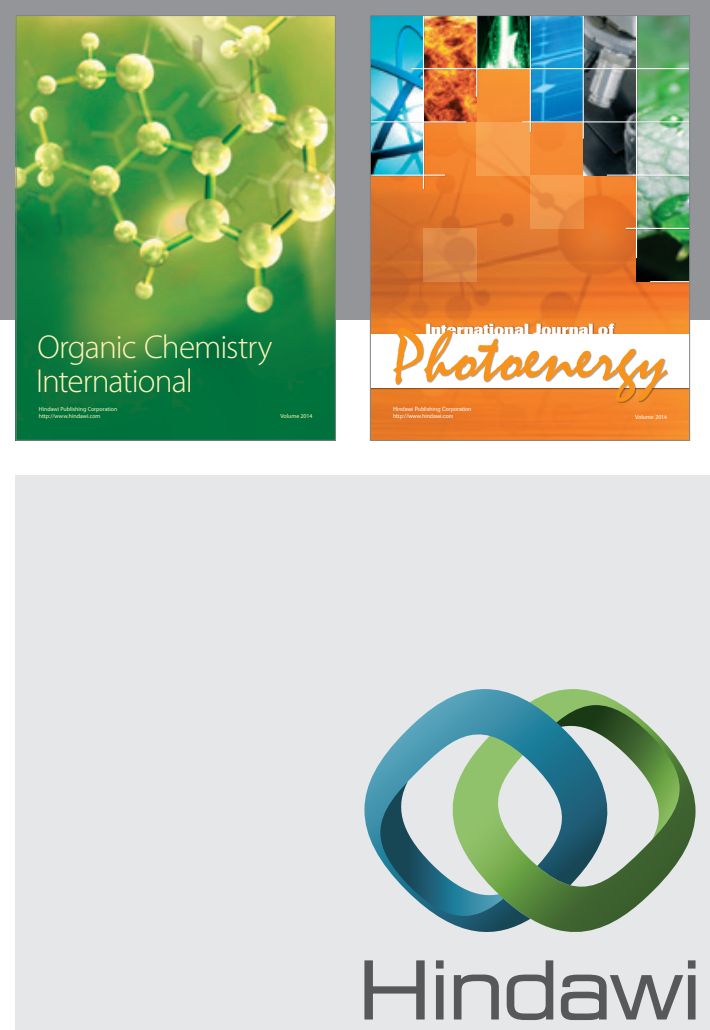

Submit your manuscripts at

http://www.hindawi.com
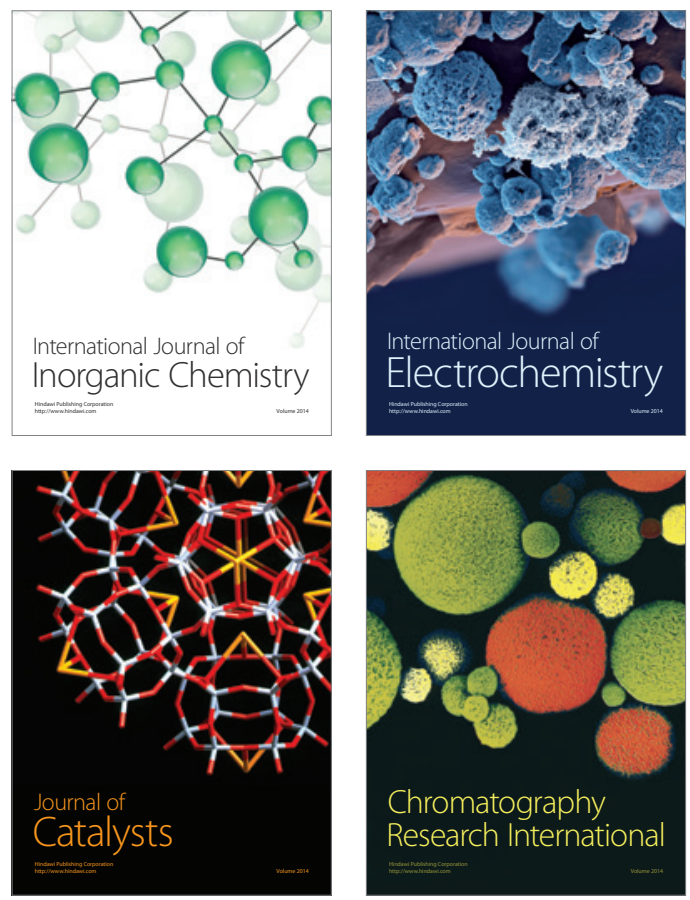
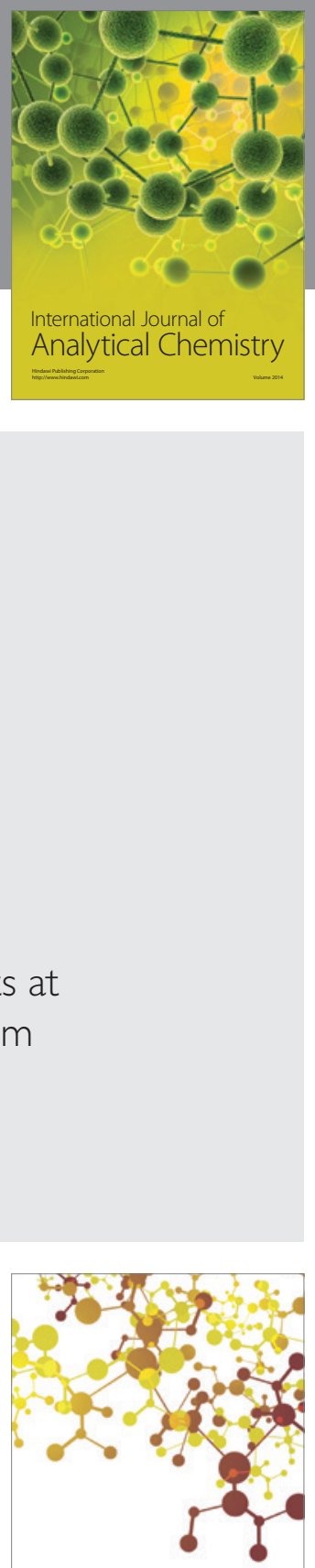

Journal of

Applied Chemistry
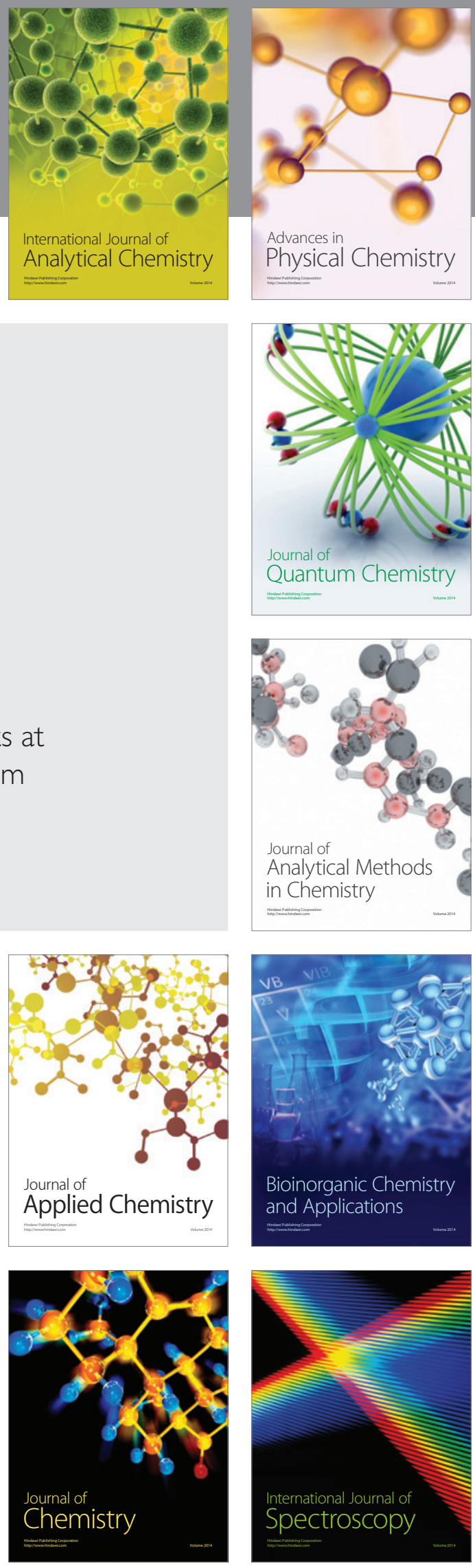